\title{
Ethnic Variation in Plate Waste at Congregate Meal Sites
}

\author{
Magnus $\mathbf{M}^{*}$ and Smith $\mathrm{M}$ \\ Department of Dietetics \& Nutrition, Florida International University, United States
}

*Corresponding author: Magnus M, Department of Dietetics \& Nutrition, Florida International University, United States, Tel: 954454 7473, E-mail: magnus@fiu.edu

Citation: Magnus M, Smith M (2016) Ethnic Variation in Plate Waste at Congregate Meal Sites. J Nutr

Health Sci 3(2): 206. doi: 10.15744/2393-9060.3.206

Received Date: April 18, 2016 Accepted Date: May 25, 2016 Published Date: May 27, 2016

\begin{abstract}
To determine how plate waste varies among African American, Jewish, and Hispanic congregate meal participants, the visual plate waste method was applied to a convenience sample of 343 trays among seven South Florida congregate meal sites. The ethnic distribution of trays was: Jewish $(n=117)$, African American $(n=101)$ and Hispanic $(n=125)$. Plate waste of food groups was measured as percent remaining in six categories. ANOVA and independent samples t-test were used to assess variation in plate waste.

Entrée (8.25\%) waste was highest and bread (.77\%) had the lowest plate waste. Plate waste was significantly higher in African American $(17.49 \%)$ and Hispanic (9.72\%) sites compared to Jewish (6.62\%) sites ( $\mathrm{p}<.001)$. African American entrée $(15.10 \pm 27.20)$ and bread $(12.87 \pm 28.20)$ waste were significantly higher than Hispanic entrée $(8.40 \pm 19.56)$ and bread $(3.80 \pm 13.86)$ waste and Jewish entree $(3.63 \pm 14.41)$ and bread $(2.56 \pm 13.63)$ waste $(\mathrm{p}<.001)$. Steps need to be taken to reduce plate waste at non-White congregate meal sites by accommodating their ethnic preferences.

Keywords: Plate Waste; Congregate Meal Sites; Dietary Guidelines
\end{abstract}

\section{Introduction}

According to the Department of Elder Affairs, it is estimated that in Florida alone, roughly 85,000 seniors aged 60 and older, receive meals funded from the Older Americans Act (OAA) [1]. As a result of the Older Americans Act (OAA), which was passed in 1965, states were given federal funding to ensure that seniors had the necessary resources to receive nutritionally adequate meals, in both in-home and congregate settings [1]. According to the Administration on Aging, the budget allocated towards the fiscal year of 2011 was $\$ 2.4$ billion to be divided among the "six cores" of the program, which included nutrition and screening preventatives among other senior targeted causes [1]. Of the $\$ 2.4$ billion, an estimated $\$ 440$ million was utilized towards national congregate meal sites, of which 39 million was received by the state of Florida [1]. Nationally the make-up for congregate meal site participants is: $6.7 \%$ Hispanic, 62.4\% White, and 11.4\% Black [2]. In Florida, the ethnic makeup of congregate meal site participants is as follows: $26 \%$ Hispanic, $48.7 \%$ White, and $23 \%$ Black, illustrating the increased proportion of Floridian nonWhites who utilize this program [3]. Roughly 50\% of home delivered meal recipients and 33\% meal site participants live below the federal income poverty level [4]. Currently an estimated $9 \%$ of seniors are living in poverty [5]. The goals of congregate meals are: 1. to provide much needed social interaction 2. to provide a hot meal (made up of at least one third of the Dietary Guidelines for Americans) to an age group that is particularly vulnerable to isolation and malnutrition 3. to delay institutionalization, 4. to provide nutrition education [1].

While congregate meals are mandated to offer at least one third of the Dietary Guidelines for Americans, the assumption that the nutrient content of a congregate meal represents nutrient intake by program participants is unwarranted. Measuring plate waste is important because: 1) it quantifies which foods were more likely to be discarded and not ingested, and 2) it represents an improvement opportunity for recipe modification by program staff and taste testing by participants. Measuring plate waste by ethnicity identifies which ethnic sites are in greatest need of recipe modification. As the United States older non-white population becomes increasingly diverse, assessing and reducing plate waste in congregate meal sites represents an opportunity for greater efficiency of the $\$ 440$ million which were allocated to the program nationally.

The need to assess ethnic variation in plate waste at congregate meal sites is driven by several factors. First, although the energy needs for this age group decrease with age, one out of every four seniors is under nourished [6]. Second, by 2050, 50\% of the US population is expected to be non-White [7]. Third, the over 60 population is expected to increase from 57 million seniors in 2010 to an estimated 112 million seniors in 2050 [8]. Fourth, the non-White population of older adults is expected to increase from 12 million seniors in 2010 to roughly 48 million seniors in 2050 [8]. 
In addition to the higher proportion of seniors that reside in Florida, (17.6\% of individuals aged 65 and older populate the state versus the national 13.3\%) [7]. Another unique feature is the amount of diversity of the state's residents. This ethnic diversity can be easily witnessed in the southern part of the state which is made up of White, Black, and Hispanic residents. According to the United States Census, between 2000 and 2009 there was a 24\% increase in the number of Blacks and Hispanics combined [8]. Furthermore, Hispanics represent $22.9 \%$ of the state, compared to the national average of $16.7 \%$. Similarly, Blacks represent $16.5 \%$ of Floridians, compared to $13.1 \%$ nationally [8]. In Broward and Miami-Dade counties, Blacks represent $27.4 \%$ of the population (compared to $19.3 \%$ nationally); Hispanics represent $25.8 \%$ of the population (compared to $64.5 \%$ nationally); and Whites represent $66.7 \%$ of the population (compared to $77.5 \%$ nationally) [8].

Plate waste in any food assistance program such as congregate meal sites is associated with reduced overall program efficiency. Any strategy which can reduce plate waste may not only improve program efficiency, it may also be associated with improved nutrient intake and nutritional status among program participants. Since the non-white older population is expected to quadruple from 12 million in 2010 to 48 million by 2050, the need to assess plate waste in congregate meal sites by ethnicity may increase as demand for the program increases [8]. Nevertheless, there are no published studies on ethnicity and plate waste in congregate meal sites.

As there is great diversity witnessed among the state's inhabitants, there are varied food ways among the ethnicities. According to Health Promotion in Multicultural Populations, Compared to non-Hispanics, Hispanics are likely to consume more rice and less pasta compared to non-Hispanic Whites.9 Hispanics are twice as likely to consume whole milk as skim and low fat milk [9]. Hispanics also consume more fruits than vegetables, with the exception of tomatoes [9].

The dietary patterns of Jewish Americans range from those that adhere to strict Kosher foods, consume other ethnic foods, or simply engage in the standard American diet [10]. In America, the two major types of Jewish groups are the Ashkenazi (originating from the Jewish who settled in France, Germany, and Eastern Europe) and the Sephadrim (originating from the Jewish who settled in Spain, Portugal, Northern Africa and the Middle East) [10]. Examples of common foods consumed by this ethnicity include barley, quinoa, couscous, legumes, dates, figs, grapes, brisket, chicken liver, and whitefish [10].

In regards to African Americans, the methods of cooking include boiling, frying, and roasting as a result of cooking methods used among some of the first African Americans who came to America as slaves [10]. Many African Americans consume foods coined "soul foods" - pigs' feet, chitterlings (pig intestine), pickles, pickled eggs which tend to be made from inexpensive food items that are prepared in such a way that renders the food very dense in calories, salt, sugar and fat [10]. Approximately 50\% of Blacks in Broward county are Caribbean American who consume diets composed of starchy root vegetables (plantains, yucca), rice, beans, and meat [10]. Common dishes consumed by this ethnicity include cassava bread, black beans and white rice, seasoned shredded beef, twice-fried green plantains and café con leche [10]. These different diets also play a role in the health of those consuming them $[11,12]$.

Although these congregate meal site programs strive to serve seniors in need, many seniors are not utilizing these programs, and as a result participation is declining. Several issues have been identified in the loss of senior participation including transportation, lack of knowledge of the programs offered, and food/menu items offered [6].

In Florida in 2011, 40,223 patrons were being served in meal sites within the site, but in 2013 a projected 32,582 will be served [3].

Plate waste studies have been conducted among older adults in long-term care facilities [13]. The results from such studies may allow for the proper modifications to be made to reduce plate waste and improve nutritional status of program participants. However, no published studies have assessed for plate waste within ethnically diverse congregate meal sites. These data could aid in the modification of the specific food items that contribute to the most waste within a particular ethnicity, in turn ensuring the senior consumes adequate nutrients, and waste at the sites is minimized.

The fact that Florida is a state that is composed of a higher number of seniors as well as a great number of non-Whites seen in the Southern part renders South Florida a prime setting to determine plate waste for the elderly ethnic residents that participate within a congregate meal site program $[7,8]$. Therefore, the purpose of this study is to determine how plate waste varies among ethnically diverse congregate meal sites in South Florida.

The hypotheses under investigation include:

1) Plate waste will be higher among Hispanic sites compared to White or Black congregate meal sites. Casual observation revealed that plate waste was higher in Hispanic than White or Black congregate meal sites.

2) Plate waste will be the highest for vegetables and lowest for desserts in meal sites. Traditionally, vegetable plate waste has been highers for vegetables and lower for desserts in meal sites.

3) Plate waste will be lower for meals among predominantly White congregate meal sites compared to Black and Hispanic sites. Direct observation of lower plate waste in White sites than Black or Hispanic sites led to this hypothesis. 


\section{Literature Review}

Studies have assessed the nutritional adequacy of meals provided in nursing homes [13]. However few published studies have described plate waste in congregate meal sites and there are no studies which have examined how plate waste varies with ethnicity.

Hayes, et al. conducted one of the only plate waste studies in a senior setting that makes mention of the participant's race [14]. The waste produced by two different foodservice systems, conventional (on site) and commissary (outside source) in five different senior nutrition center was assessed [14]. The data were collected for five days and sampled 257 patrons (198 were White and 54 were Black) who were 80 years and older [14]. The participants were asked to fill out a questionnaire, which focused on demographics, food preferences, and a food rating (poor, fair or excellent) [14]. Although there was no significant difference in plate waste between conventional and commissary foodservice systems, plate waste averaged 6.9\% [14]. Researchers reported no significant differences in plate waste by race [14].

Nichols, et al. assessed plate waste among 60 randomly selected seniors who were aged 60 and older and living in a retirement living center in Tulsa, Oklahoma [13]. The researchers collected data on breakfast, lunch, and dinner for three days and used digital scales to calculate the pre/post weights of the food items [13]. The researchers found that the subjects had not eaten roughly $20 \%$ of the food provided, and that fats made up the highest percentage of waste, followed by vegetables, meats, starches, milk, fruits and desserts with the least waste $(31 \%, 29 \%, 27 \%, 25 \%, 20 \%, 12 \%, 11 \%$ respectively) [13]. Despite the fact that between 1990 and 2000, prior to the study, the Black population in Tulsa increased by $27 \%$ of Blacks and the Hispanic population by $199 \%$, the relationship between ethnicity and plate waste was not assessed [15].

Wiener, et al. assessed the effectiveness of Title III-D, the segment of the Older Americans' Act which is administratively responsible for congregate meal sites by examining how funds were allocated and the impact of the program on participants' [16]. The researchers utilized case studies, expert interviews, and literature reviews of the literature and concluded that there was significant evidence to suggest that the activities implemented by this program could lead to a more independent and healthier life of the participants [16]. Although the findings show that the programs can have a positive impact on the participants utilizing the services, according to the Congressional Research Service (CRS), the Government Accountability Office found in 2008 that the program provided meals for some, but not for most of the low income seniors who could benefit from them $[4,16]$.

Currently $79 \%$ of congregate meal site participants are $200 \%$ below the DHHS (Department of Human and Health Services) poverty line, and $90 \%$ of home delivered meal recipients fall into this category as well [3]. The CRS stated minimal participation of low-income seniors in congregate meal program could be related to home-delivered meals, lack of knowledge or awareness of congregate meal sites and more importantly, the seniors' lack of desire for the meals being offered and the time at which meals are served [4].

In the study conducted Nichols, et al. it could be seen that the amount of plate waste generated by seniors was an estimated 20\%, with fats, vegetables, meats and starches producing the most waste [13]. This high percentage of waste could have the potential for serious implications for the financial health and future of government funded programs. These results illustrate an urgent need to increase the participant's desire to consume enough of the food groups to meet the necessary dietary guidelines for this age group [12].

\section{Methods}

Permission from Florida International University's Institutional Review Board (IRB) was granted for this study. Permission to conduct the study was sought from the congregate meal site of a local county.

\section{Subjects}

A convenience sample of predominantly Jewish, Black and Hispanic congregate meal sites was derived from the list of sites in a South Florida county. Plate waste for the luncheon meal was assessed for all sites. The sites were composed of two predominately Black, two predominately Hispanic, and one Kosher site. This cross-sectional observational study assessed plate waste from at least 105 meals each from Jewish, Black and Hispanic sites from patrons who attend the predominantly Jewish, Black and Hispanic congregate meal sites. The sample of 105 meals from each ethnicity was the amount of observations needed to determine whether a medium effect would be witnessed a power level of $95 \%$ was utilized. Patrons were asked to leave their trays in a particular area for immediatessessment of plate waste, and in sites of high volume the researcher stood by the only garbage can to asses for waste.

\section{Data Collection}

The study took place during several weeks, where for a single day data was collected from a single site. A sample of 105 meals from each ethnicity was needed for a medium effect would be witnessed. This resulted in a minimum of 315 observations required, although 343 were obtained. Plate waste was assessed by observing the contents left on the patron's tray upon completion of their meal. 
Participants received food in the same fashion as before the assessment of plate waste-they received food trays at their designated table. The visual plate waste method was used to assess the food groups on the participant's tray (entrée, fruit, vegetables, bread, dessert, and milk). Individuals were asked to leave their trays at their table upon completion of their meal, which the researcher will then visually assessed to determine whether $25 \%, 50 \%, 75 \%$ or $100 \%$ of the particular food item was left as waste. However in sites of large volume participants were asked to show the researcher their tray before disposing of the food items.

A pilot study was conducted consisting of 21 meals in one of the congregate meal sites.

\section{Statistical Analysis}

The descriptive statistics (frequencies, means, standard deviations, ranges and proportions) were critically analyzed. For the purposes of this study the two vegetables were combined as a single vegetable to be compared among the other food items. In order to calculate the percent of each food item, all the foods weights were converted to grams. The mean of plate waste and the waste of the individual food items were calculated among each site and compared among each other using ANOVA. These values were computed using SPSS (Version 11.5, 2003, SPSS Inc., Chicago, Il). A significance level of p<.05 was set Table 1.

\begin{tabular}{|c|c|}
\hline Site & Participants (Number, \%) \\
\hline Predominately Black Sites \\
\hline Hepburn & $38(11.1 \%)$ \\
\hline North West Women's Federated & $63(18.2 \%)$ \\
\hline \multicolumn{2}{|c|}{ Predominately Hispanic Sites } \\
\hline North West Focal Point & $29(8.5 \%)$ \\
\hline South West Focal Point & $35(10.2 \%)$ \\
\hline South West Focal Point & $61(17.8 \%)$ \\
\hline \multicolumn{2}{|c|}{ Predominately White Sites } \\
\hline Cantor & $58(16.9 \%)$ \\
\hline Cantor & $59(17.2 \%)$ \\
\hline
\end{tabular}

Table1: Ethnic Distribution of Congregate Meal Sites $(n=343)$

\section{Results}

The study sample included a total of 343 assessments of lunch meals collected from participants in a congregate meal site program. The ethnicities: Black (29.30\%), Hispanic (36.50\%), and White (34.10\%) were evenly distributed among the sites. Five sites were assessed for plate waste (two sites were assessed on two separate occasions to gain the minimum of 105 plates). Plate waste was assessed among 117 trays among Blacks, 101 trays among Hispanics, and 117 trays among Whites. Due to the high volume of subjects in several of the sites milk waste percentages were not recorded for 127 participants. However, mean plate waste, the percent of the volume of uneaten food, between trays with milk waste $(M=10.94)$ and mean plate waste for trays without milk waste $(M=11.03)$ were not significantly different.

All 343 participants received an entrée, two vegetables, and bread, while 280 participants received fruit, and 98 received dessert. Mean plate waste by food category are shown in Table 2.

\begin{tabular}{|c|c|c|}
\hline Food Category & Mean \% Plate Waste & Standard Deviation \\
\hline Vegetable & 13.10 & 24.06 \\
\hline Milk & 4.05 & 16.47 \\
\hline Fruit & 7.68 & 22.86 \\
\hline Entrée & 8.75 & 21.11 \\
\hline Dessert & 2.81 & 13.84 \\
\hline Bread & 6.04 & 19.63 \\
\hline $\begin{array}{c}\text { Total Mean \% } \\
\text { Plate Waste }\end{array}$ & 10.95 & 15.99 \\
\hline
\end{tabular}

Table 2: Mean Percentage Plate Waste by Food Category

When comparing the percent waste of vegetables versus desserts a total of 97 plates were assessed (as a result of ninety-seven participants receiving a dessert in the form of a cookie). The mean percent vegetable waste $(M=5.91)$ was higher than the mean percent dessert waste $(M=2.81)$. However, a paired-samples t-test was conducted to evaluate the difference between the vegetable plate waste and dessert plate waste. There was a marginally significant difference between vegetable waste $(\mathrm{M}=5.91, \mathrm{SD}=12.34)$ and dessert waste $(\mathrm{M}=2.81, \mathrm{SD}=13.85)$; $(97)=1.72, \mathrm{p}=.09$ (two-tailed). In other words, results suggest a slightly higher plate waste for vegetable plates compared to the dessert plates. 


\begin{tabular}{|c|c|c|c|}
\hline Food Category & Mean \% Plate Waste & Standard Deviation & p-value (n=97) \\
\hline Entrée $^{*}$ & 8.25 & 19.34 & $\mathrm{p}<.003$ \\
\hline Vegetable $^{*}$ & 5.97 & 12.39 & $\mathrm{p}<.001$ \\
\hline Fruit & 3.87 & 16.67 & \\
\hline Dessert & 2.84 & 13.91 & \\
\hline Milk & 2.58 & 12.75 & \\
\hline Bread $^{*}$ & 0.77 & 4.35 & $\mathrm{p}<.001$ \\
\hline \multicolumn{3}{|c|}{ Wilks' Lambda $=.74, \mathrm{~F}(5,92)=6.46, \mathrm{p}<.001$} \\
\hline
\end{tabular}

Table 3: Mean Percentage Plate Waste Among Food Categories $(\mathrm{n}=97)$

When comparing all food category together a one-way repeated measures ANOVA was conducted to compare the amount of waste for the six different food categories (entrée, vegetable, fruit, grain, milk and dessert). The means and the standard deviations are presented in Table 3. This data confirms the hypothesis that vegetable waste would be higher than dessert waste however, refutes the hypothesis that vegetable waste would be the highest waste (entrée waste was higher) and dessert waste would be the lowest (bread and milk had lower waste).

\begin{tabular}{|c|c|c|c|}
\hline Site Ethnicity & Mean \% Plate Waste & Standard Deviation & p-Value \\
\hline Black $^{\star}(\mathrm{n}=101)$ & 17.49 & 21.94 & \\
\hline Hispanic $^{*}(\mathrm{n}=125)$ & 9.72 & 12.10 & $\mathrm{p}=.001$ \\
\hline White $^{*}(\mathrm{n}=117)$ & 6.62 & 11.16 & $\mathrm{p}<.001$ \\
\hline Total $(\mathrm{n}=343)$ & 10.95 & 15.98 & \\
\hline
\end{tabular}

ANOVA: $\mathrm{F}(2,340)=14.13$, $\mathrm{p}<.05$

Table 4: Mean Percentage Plate Waste by Ethnicity

Variation among mean plate waste by ethnicity is shown in Table 4. The data refutes the hypothesis that plate waste assessed in Hispanic sites would be significantly different from non-Hispanic sites, although the waste from the Black sites was significantly higher there was no significance difference compared to the White sites.

An independent samples t-test revealed that there was no significant difference in the percent of plate waste for Hispanics and non-Hispanics as shown in Table 5. However, there was a significant difference in the percent of plate waste for Whites and nonWhites. This result indicates that there was significantly lower plate waste for White sites compared to non-White sites, confirming the hypothesis that lower waste would be witnessed in White sites.

Independent samples t-test non-Hispanic versus Hispanic: $\mathrm{t}(341)=1.20, \mathrm{p}=.23$

Independent samples t-test non-White versus White: $\mathrm{t}(341)=4.21, \mathrm{p}<.001$

\begin{tabular}{|c|c|c|c|}
\hline Site Ethnicity & Mean \% Plate Waste & Standard Deviation & $\mathbf{p}$-Value \\
\hline Non-Hispanic $(\mathrm{n}=218)$ & 11.66 & 17.83 & $\mathrm{p}=.23$ \\
\hline Hispanic $(\mathrm{n}=125)$ & 9.71 & 12.10 & $\mathrm{p}=.23$ \\
\hline Non-White $^{*}(\mathrm{n}=226)$ & 13.20 & 17.59 & $\mathrm{p}<.001$ \\
\hline White $^{*}(\mathrm{n}=117)$ & 6.62 & 11.16 & $\mathrm{p}<.001$ \\
\hline
\end{tabular}

Table 5: Mean Percentage Plate Waste Among Hispanics,non-Hispanics, aWhites and non-Whites

\begin{tabular}{|c|c|c|c|c|}
\hline Black $(\mathbf{n}=101)$ & Hispanic $(\mathbf{n}=125)$ & White $(\mathbf{n}=117)$ & \multicolumn{2}{|c|}{ F-Value } \\
\hline Entrée $^{*}$ & $15.10+-27.20^{\mathrm{a}}$ & $8.40+-19.56^{\mathrm{b}}$ & $3.63+-14.41^{\mathrm{b}, \mathrm{c}}$ & $8.36^{*}$ \\
\hline Vegetable $^{*}$ & $20.38+-31.10^{\mathrm{a}}$ & $14.91+-24.20^{\mathrm{a}}$ & $4.88+-24.17^{\mathrm{b}}$ & $12.61^{*}$ \\
\hline Bread $^{*}$ & $12.87+-28.20^{\mathrm{a}}$ & $3.80+-13.86^{\mathrm{b}}$ & $2.56+-13.63^{\mathrm{b}, \mathrm{c}}$ & $9.18^{\star}$ \\
\hline Fruit $^{*}$ & $.66+-4.05^{\mathrm{a}}$ & $4.20+-13.37^{\mathrm{a}}$ & $13.68+-31.57^{\mathrm{b}}$ & $7.60^{*}$ \\
\hline Milk $^{*}$ & $6.58+-19.87^{\mathrm{a}}$ & $10.25+-25.57^{\mathrm{a}}$ & $0.00+-0.00^{\mathrm{b}}$ & $8.91^{\star}$ \\
\hline Dessert & $0.00+-0.00$ & N/A & $4.66+-17.66$ & 2.71 \\
\hline
\end{tabular}

Table 6: Mean Percentage Plate Waste among Ethnicities By Food Groups Food Group Mean Percentage Plate Waste

Mean plate waste distribution among ethnicities is shown in Table 6. For entrée and bread waste, the Hispanic and White sites had significantly lower waste then the Black sites. Vegetable waste was significantly higher in the Black and Hispanic sites as compared to the White sites. White sites had significantly higher fruit waste as compared to non-White sites. Milk waste significantly lower in White sites when compared to Hispanic sites, but showed no significant difference when compared to Black sites. There was no significant difference between dessert waste among the Black and White sites. 


\section{Discussion}

The results of this research show that mean waste for all sites was roughly $11 \%$, which differed from the $20 \%$ mean waste determined by Nichols, et al. in a retirement center setting [13]. Hayes, et al. found a mean waste of roughly $7 \%$ in a Senior Nutrition Center [14]. The target population of both Nichols, et al. and Hayes, et al. were white [13,14]. The difference among this study and the Nichols, et al. study could be that the Nichols, et al. assessed for 3 meals (breakfast, lunch, and dinner) among three days [13]. The mean plate waste for lunch was not given, therefore a large mean plate waste in the breakfast or dinner meals could have easily affected the mean waste calculated. In this study plate waste was the highest for the entrée group and the lowest for the bread group [13]. These findings differed from the results found by Hayes, et al and Nichols, et al. which found the most waste in the vegetable group and the least seen among the fruit group $[4,13,14]$. This difference can be attributed to individual taste preference as well as the differences in menu options.

In regards to waste and ethnicity this study found that the highest mean plate waste was found in the minority sites, the Black sites attributing the highest amounts of waste. This difference in plate waste among ethnicities could be a result of lack of appealing menu options to minority patrons in combination with the fact that the White site (composed of 100\% Jewish participants) offered menu items, personalized for those following a Kosher lifestyle.

Since the lowest plate waste was found in predominantly Jewish sites, an increase in a variety of ethnic foods may lower percentage of waste in minority congregate meal sites. According to the US Census, $26 \%$ of Black and 20\% of Hispanic American citizens live in poverty. However, $20 \%$ of Black and 26\% Hispanic Americans who are living below the poverty level are registered with programs which are funded by the Older Americans Act [2].

Strengths of this study included a large sample size of 343 plate waste observations, and the use of a single observer to avoid bias when assessing plate waste. Another strength of this study was that the plate waste among three ethnicities. There were several limitations of this study. First, a single congregate meal site was assessed on a given day so the same menu options could not be compared between each ethnicity. Also, as a result of the menu offerings, out of the 343 observations, 97 had all six food categories included (entrée, vegetable, fruit, bread, dessert, and milk). Second, physical limitations (denture use, issues with swallowing etc.) of the participants were assumed to be constant among all three ethnicities and were not taken into account. Third, food, which was shared among participants, or food, which was taken out of the site, was not assessed. Although the prevalence of chronic diseases varies by ethnicity, the presence of multiple chronic diseases was also not taken into account.

\section{Conclusion}

Since overall plate waste was lower among Jewish sites (6.62\%), and higher in non-Jewish sites (13.20\%), innovative approaches need to be identified to reduce plate waste and overall efficiency in African American, Caribbean American and Hispanic congregate meal sites. Since plate waste was significantly lower at Jewish sites where Jewish foods and Kosher laws were upheld, non-Jewish menus may need to accommodate the ethnic preferences of the target population. Taste testing data of African American, Caribbean American and Hispanic foods may be necessary to inform menu selection and reduce plate waste. Menu selection may need to focus on entree, vegetable, and bread options since plate waste for these meal components were significantly higher in both Black and Hispanic sites compared to Jewish sites. As the non-White population of older adults continues to increase, reductions in plate waste could not only improve nutritional status, it also increases program efficiency and effectiveness. More efficient use of existing congregate meal funds may make it easier to not only increase funding but also accommodate older adults who are on the waiting lists for congregate meal programs.

\section{References}

1. Nutrition Services (N.d.) Administration on Aging. Retrieved September 23, 2012.

2. AGID - Data-at-a-Glance - State Program Reports. (n.d.). AGID - Home. Retrieved January 10, 2012.

3. 2011 NAPIS Report. (n.d.). Elder Affairs. Retrieved January 11, 2013

4. Colello, K. (n.d.). Older Americans Act: Title III. Congressional Research Service. Retrieved January 10, 2013.

5. About Poverty - Highlights - U.S Census Bureau. (n.d.). Census Bureau Homepage. Retrieved February 1, 2013.

6. Nutrition and Aging. (n.d.). Nutrition and Aging. Retrieved November 5, 2012.

7. Centers for Disease Control and Prevention. Centers for Disease Control and Prevention. Retrieved September 23, 2012.

8. Census Bureau Homepage. Census Bureau Homepage. Retrieved September 23, 2012.

9. Kline MV, Huff RM (2007) Health promotion in multicultural populations: a handbook for practitioners and students $2^{\text {nd }}$ ed. Los Angeles: Sage Publications.

10. Goody CM, Drago L (2010) Cultural food practices. Chicago, Ill.: American Dietetic Association.

11. Drake V (n.d.). Linus Pauling Institute at Oregon State University. Linus Pauling Institute at Oregon State University. Retrieved January 5, 2013.

12. Nutrition facts, calories in food, labels, nutritional information and analysis - NutritionData.com . (n.d.). Nutrition facts, calories in food, labels, nutritional information and analysis - NutritionData.com . Retrieved January 16, 2013.

13. Nichols P, Porter C, Hammond L, Arjmandi B (2002) Food intake may be determined by plate waste in a retirement living center. J American Dietetic Association, 102. Retrieved September 16. 
14. Hayes J, Kendrick O (1995) Plate Waste and Perception of Quality of Food Prepared in Conventional vs Commissary Systems in the Nutrition Program for the Elderly. J American Dietetic Association 95: 585-6.

15. 2012 Tulsa Demographics (n.d.). Tulsa Chamber. Retrieved September 21, 2012.

16. Wiener J (n.d.). Assessment of Title III-D of the Older. AoA. Retrieved January 10, 2013.

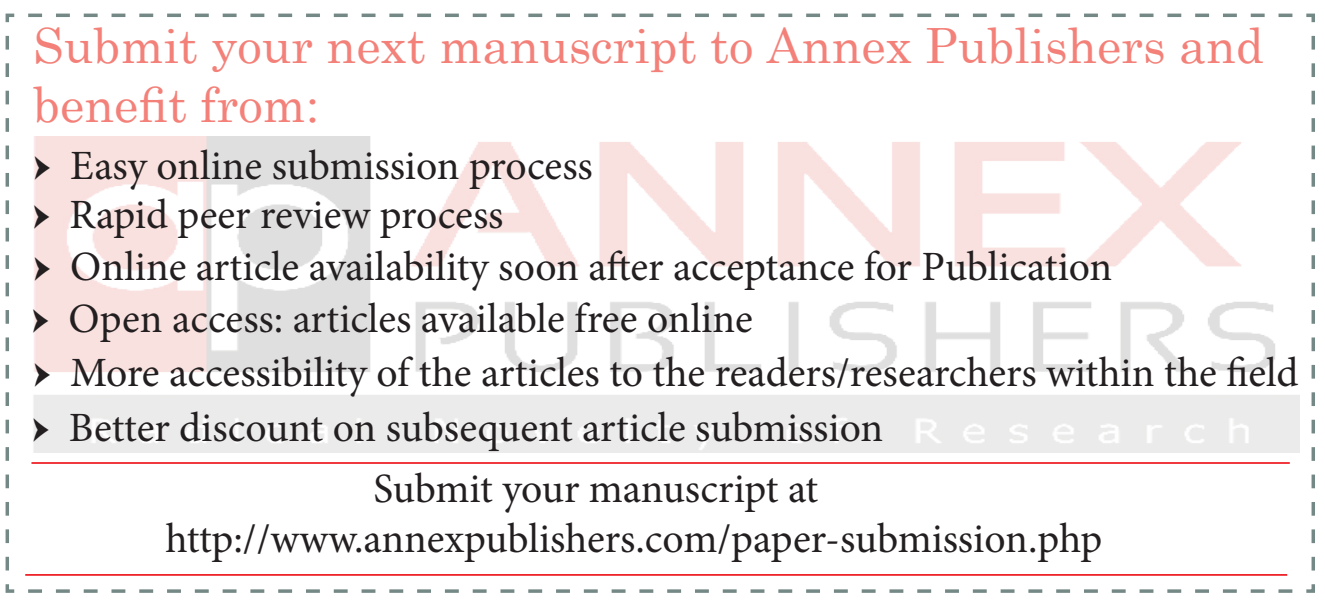

